Case Report

\title{
Thyroid Sporadic Goiter with Adult Heterotopic Bone Formation
}

\author{
Adriana Handra-Luca, ${ }^{1}$ Marie-Laure Dumuis-Gimenez, ${ }^{2}$ \\ Mouna Bendib, ${ }^{1}$ and Panagiotis Anagnostis ${ }^{3}$ \\ ${ }^{1}$ Service d'Anatomie Pathologique, APHP GHU Avicenne, UFR Médecine, Université Paris Nord Sorbonne Cité, \\ 125 rue Stalingrad, 93009 Bobigny, France \\ ${ }^{2}$ Service Medecine Nucleaire, APHP GHU Avicenne, 93009 Bobigny, France \\ ${ }^{3}$ Division of Endocrinology, Police Medical Centre, Monastiriou 326, 54627 Thessaloniki, Greece \\ Correspondence should be addressed to Adriana Handra-Luca; adriana.handra-luca@hotmail.com
}

Received 7 August 2015; Accepted 8 November 2015

Academic Editor: Osamu Isozaki

Copyright (C) 2015 Adriana Handra-Luca et al. This is an open access article distributed under the Creative Commons Attribution License, which permits unrestricted use, distribution, and reproduction in any medium, provided the original work is properly cited.

Thyroid heterotopic bone formation $(\mathrm{HBF})$ in goiter is a rare finding. Five thyroid resection specimens were analyzed for HBF. The results were correlated with clinicomorphological features. All patients were women (33-82 years). The preoperative diagnosis was thyroid goiter or nodule. Treatment consisted in thyroidectomy and lobectomy (3 and 2, resp.). Microscopy showed sporadic nodular goiter. Malformative blood vessels and vascular calcifications were seen in intra- and extrathyroid location (5 and 3, resp.). The number and size of HBFs (total: 28) ranged between 1 and 23/thyroid gland (one bilateral) and 1 and $10 \mathrm{~mm}$, respectively. Twelve HBFs were in contact with the thyroid capsule. Most were extranodular (21, versus 6 intranodular). The medical history was positive for dyslipidemia, hyperglycemia, renal dysfunction, and hyperuricemia (2,3, and 3 cases and 1 case, resp.) without any parathyroid abnormality. In conclusion, thyroid HBF may be characterized by subcapsular or extranodular location, various size (usually $\geq 2 \mathrm{~mm}$ ), and vascular calcifications and malformations. Features of metabolic syndrome and renal dysfunction may be present, but their exact role in the pathogenesis of HBFs remains to be elucidated.

\section{Introduction}

Heterotopic bone formation (HBF) is defined as extraskeletal bone formation. Thyroid HBF, frequently designated as bone metaplasia, occurs rarely in the thyroid, being reported both in goiter and in tumors such as adenomas and carcinosarcomas [1-10]. To our knowledge, seven cases of thyroid sporadic goiter with complete, adult $\mathrm{HBF}$ are reported in the English medical literature $[2,4,7-10]$. Here we report five additional cases of complete, adult HBF occurring in the context of sporadic thyroid nodular goiter.

\section{Methods}

Five thyroid resection specimens were analyzed for $\mathrm{HBF}$ as defined by the presence of lamellar bone trabeculae delimiting fat or fibrofat tissue with hematopoietic elements and capillaries. The number, size, and location of HBF foci (subcapsular or not, intranodular or not) were tabulated. Foci of ossification consisting only of bone trabeculae were considered separately. Thyroid parenchyma was also analyzed for nodules (hyperplastic, adenoma-type, or carcinoma), atrophy, necrosis, fibrosis, calcifications, inflammation, and vascular lesions (pseudoangioma lesions or vascular conglomerates, thrombosis, intima/media fibrosis and hyperplasia, and calcifications). Two thyroids were sampled quasientirely (Cases 1 and 2). Serial and/or multistep tissue sections were analyzed for the HBFs. The results were analyzed with regard to clinicomorphological features. The rank correlation Kendall test was used for evaluating the statistical significance of correlations (Medcalc v14, Belgium). A $P$ value of less than 0.05 indicated statistical significance. 


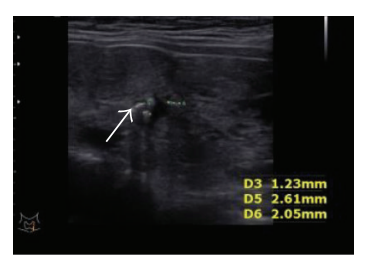

(a)

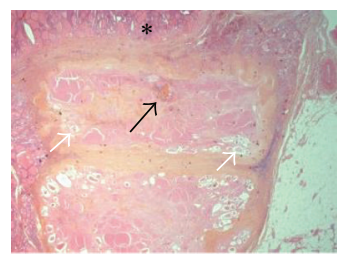

(e)

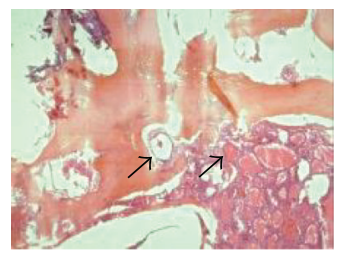

(i)

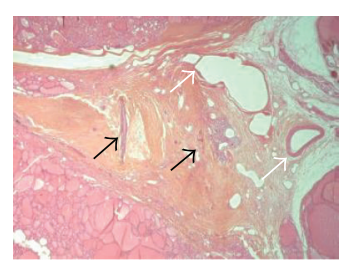

(m)

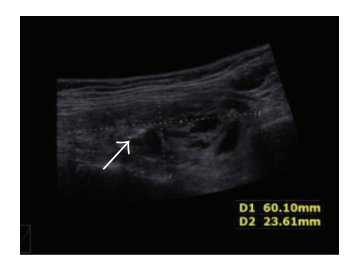

(b)

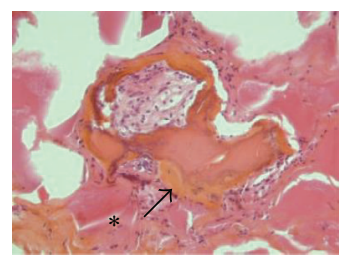

(f)

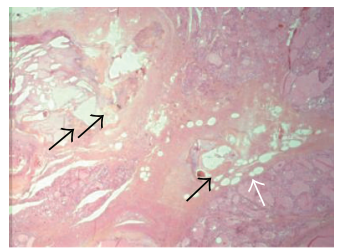

(j)

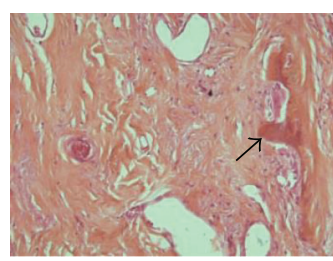

(n)

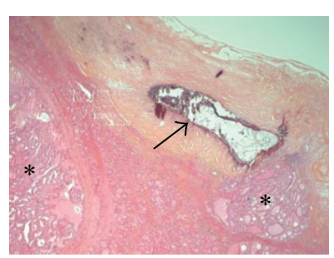

(c)

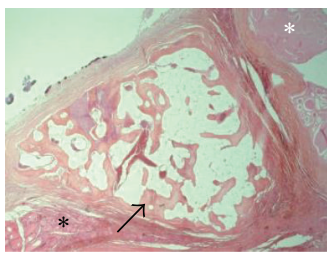

(g)

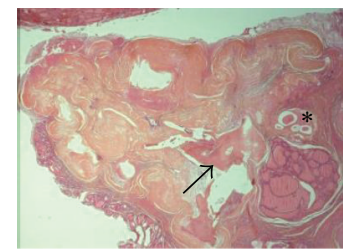

(k)

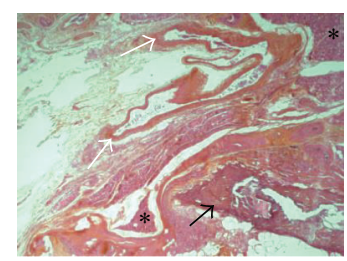

(o)

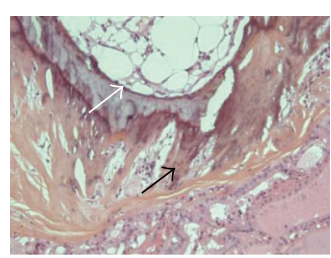

(d)

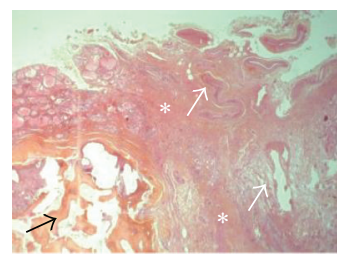

(h)

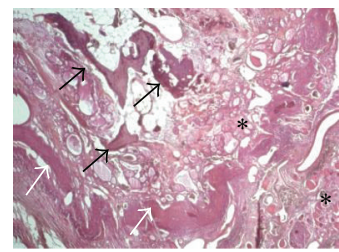

(1)

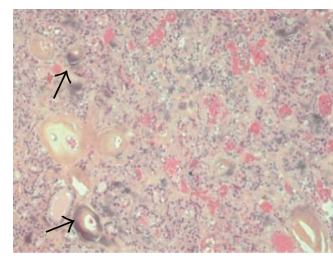

(p)

Figure 1: At ultrasound examination the thyroid showed several nodules and micro- and macrocalcifications (a, b: white arrows, Case 1). Microscopy showed in this case a HBF (heterotopic bone formation) focus in a thick rim of dense fibrosis (c, d: black arrow/HBF, asterisks/thyroid vesicles, and white arrow/intertrabecular fat with hematopoietic elements). Several HBFs were seen in Case 2 (e-k). A subcapsular nodule, largely fibrotic and atrophic, contained an infracentimetric HBF (e-f: black arrow/HBF, white arrow/nodular atrophic vesicles, and asterisk/reactive thyroid follicles). Another subcapsular HBF showed triangular shape and was situated in contact with an atrophic goiter nodule (g: black arrow/HBF, asterisk/thyroid vesicles, atrophic for some). A 3rd HBF was situated in contact with sheetpatterned fibrosis which contained large malformative vessels (h: black arrow/HBF, asterisks/thyroid vesicles, and white arrows/vessels). For this $\mathrm{HBF}$, vesicles were at proximity and contact of bone trabeculae (i: black arrows). A 4th HBF was situated at proximity of intrathyroid adipose cells englobed in fibrosis (j: black arrow/HBF, white arrow/adipose cells). A 5th HBF was situated in a triangular-shaped zone of fibrosis, focally undulated, with an atrophic follicular nodule at contact (k: black arrow/HBF, asterisk/atrophic nodule). In Case 3 (l) a vaguely nodular zone, containing the HBF and thyroid vesicles, was delimited by undulated connective tissue (black arrows/HBF, asterisk/thyroid vesicles, and white arrows/undulated fibrosis with large vessels at contact). In Case 4 (m-n), the thyroid contained sheet-like fibrosis with large, malformative vessels at proximity and with ossification foci ( $\mathrm{m}, \mathrm{n}$ : black arrows/ossifications, white arrows/abnormal vessels). In Case 5 (o-p) the HBF was located in the subcapsular thyroid, at proximity to large malformative vessels (intra- and perithyroid) (o: black arrow/HBF, white arrow/malformative vessels, and asterisks/thyroid vesicles). The follicular nodule, situated at distance from the HBF, contained intervesicular disperse calcifications, some in the perivascular hyaline (p: black arrows).

\section{Results}

The main features of the cases are demonstrated in Tables 1 and 2 .

Case 1. The patient (51-year-old woman) had undergone a total thyroidectomy for toxic goiter. The patient was treated with carbimazole and thyroxine for 1.5 years. The medical history was positive for arterial hypertension and tachycardia as well as for cardiomegaly. There was no evidence of anemia. Foci of micro- and macrocalcifications were observed on thyroid ultrasound examination (Figure 1). Postsurgical hypocalcemia occurred and was treated with calcium supplementation. The patient was well at postsurgical consultation (after 3 months of follow-up).

Microscopy showed sporadic multinodular goiter with malformative, large, and tortuous blood vessels (intra- and extrathyroidal) intermingled with rare nerves. There were no 


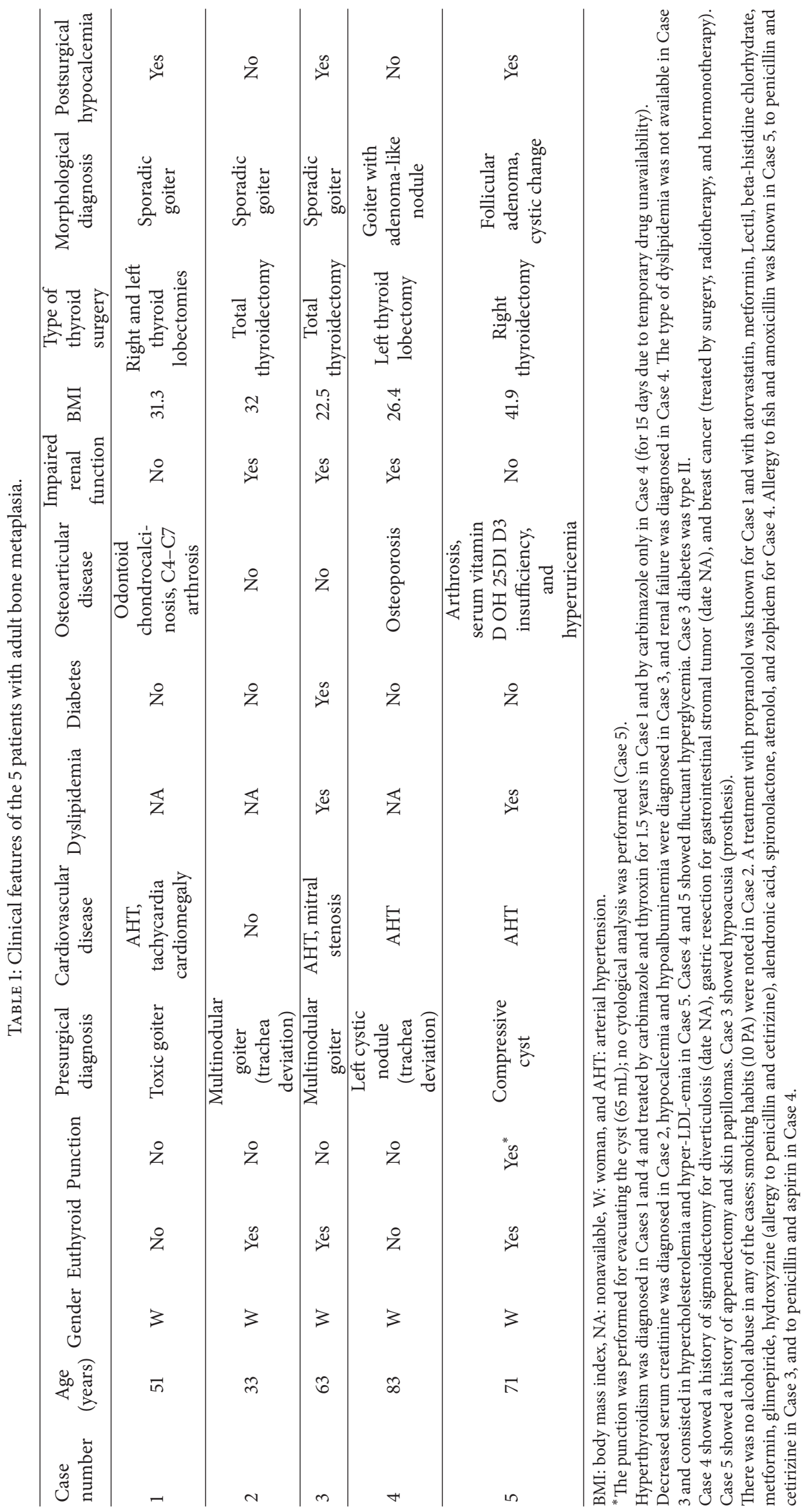


TABLE 2: Main morphological characteristics of the 5 thyroidectomy specimens.

\begin{tabular}{|c|c|c|c|c|c|c|c|c|c|}
\hline Number & $\begin{array}{l}\text { Thyroid } \\
\text { weight } \\
\text { (grams) }\end{array}$ & $\begin{array}{l}\text { Thyroid } \\
\text { volume } \\
\left(\mathrm{mm}^{3}\right)\end{array}$ & $\begin{array}{l}\text { Number of } \\
\text { HBF foci } \\
\text { (size, mm) }\end{array}$ & $\begin{array}{l}\text { Number of } \\
\text { ossification } \\
\text { foci }\end{array}$ & $\begin{array}{c}\text { Thyroid } \\
\text { calcifications }\end{array}$ & $\begin{array}{l}\text { Thyroid } \\
\text { fibrosis }\end{array}$ & $\begin{array}{c}\text { Thyroid } \\
\text { inflammation }\end{array}$ & $\begin{array}{c}\text { Vascular } \\
\text { calcifications }\end{array}$ & $\begin{array}{l}\text { Thyroid } \\
\text { adipose } \\
\text { involution }\end{array}$ \\
\hline 1 & 48 & 93.75 & $1(2.5 \mathrm{~mm})$ & 0 & 1 & Severe & Moderate & No & Multifocal \\
\hline 2 & 32 & 72 & $27(2-10 \mathrm{~mm})$ & 11 & 1 & Severe & Moderate & No & Multifocal \\
\hline 3 & 38 & 51 & $1(10)$ & 0 & $1^{*}$ & Mild & Mild & $\begin{array}{c}\text { Intra-, } \\
\text { perithyroid }\end{array}$ & No \\
\hline 4 & 115 & 195 & $\begin{array}{l}2(1 \text { and } \\
9.5 \mathrm{~mm})\end{array}$ & 14 & $1^{*}$ & Mild & Moderate & $\begin{array}{c}\text { Intra-, } \\
\text { perithyroid }\end{array}$ & No \\
\hline 5 & 43 & 180 & $1(8 \mathrm{~mm})$ & 0 & $1^{*}$ & Mild & $\begin{array}{l}\text { Mild to } \\
\text { moderate }\end{array}$ & $\begin{array}{c}\text { Intra-, } \\
\text { perithyroid }\end{array}$ & Multifocal \\
\hline
\end{tabular}

* Cases 3, 4, and 5 showed also reticular and perivascular calcifications in hyperplastic nodules.

Normal parathyroid tissue was seen in the perithyroid adipose tissue in Case 1.

vascular thromboses. Parenchymal nodules, several encapsulated, were hyperplastic and adenoma-like. Inflammation was moderate. Fibrosis was severe and extensive with a band-like pattern without extrathyroid extension. One HBF was identified $(2.5 \mathrm{~mm})$ with no ossification foci. Multifocal adipose involution was seen.

Case 2. The patient (33-year-old woman) had undergone a total thyroidectomy for goiter with trachea deviation. She was euthyroid. Smoking of 10 packs/year was noted. There was no evidence of anemia. Thyroid ultrasound examination showed foci of micro- and macrocalcifications (Figure 1). The patient was well at postsurgical consultation (after 0.5 months of follow-up).

Microscopy showed sporadic multinodular goiter with malformative, large, and tortuous blood vessels (intra- and extrathyroidal) intermingled with rare nerves. Vascular cavities with tuft-like projections were associated. There were no vascular thromboses. Parenchymal nodules, several encapsulated, were hyperplastic and adenoma-like. Several atrophic nodules, some with intranodular fibrocollagen, were also seen. Inflammation was moderate. Fibrosis was severe and extensive with a band-like pattern, containing or being at proximity of large blood vessels (intra- or extrathyroid), without extrathyroid extension. Twenty-three HBFs $(2-10 \mathrm{~mm})$ were identified with 11 ossification foci. Three extranodular HBFs were in direct contact with the capsule of fibroatrophic nodules. For two HBFs, band-like fibrosis connected malformative vessels to the HBF. On serial sections, two ossification foci revealed intertrabecular spaces and were thus diagnosed as HBFs. Multifocal adipose involution was seen as well as intrathyroid muscle tissue (the closest at $6.5 \mathrm{~mm}$ from the HBF).

Case 3. The patient (63-year-old woman) had undergone a thyroidectomy for goiter. The patient was euthyroid and was diagnosed with arterial hypertension and mitral stenosis. There was no evidence of anemia. Postsurgical hypocalcemia was treated with calcium. The patient was well at postsurgical consultation (after 1 month of follow-up).

Microscopy showed sporadic multinodular goiter with malformative, large, and tortuous blood vessels (intra- and extrathyroid) intermingled with rare nerves. There were no vascular thromboses. Parenchymal nodules, several encapsulated, were hyperplastic and adenoma-like. Calcifications of the internal elastic lamina and media (von Monckeberg sclerosis-type) were observed in the vessel wall, in periand intrathyroid locations [11]. Perivascular calcifications of calcipheresis-type were seen in hyperplastic nodules. Inflammation was mild as well as fibrosis. One HBF $(10 \mathrm{~mm})$ was identified. Abnormal blood vessels were seen around the HBF.

Case 4. The patient (83-year-old woman) had undergone left thyroidectomy for a cystic nodule with trachea deviation. The patient had been treated with carbimazole and thyroxine (15 days). The medical history was positive for arterial hypertension and osteoporosis. There was no evidence of anemia. The patient was well at postsurgical consultation (after 2 months of follow-up).

Microscopy showed sporadic multinodular goiter with malformative, large, and tortuous blood vessels (intra- and extrathyroidal) intermingled with rare nerves. Vascular cavities with tuft-like projections were associated. There were no thromboses. Parenchymal nodules, several encapsulated, were hyperplastic and adenoma-like. Calcifications of the internal elastic lamina and media (von Monckeberg sclerosistype) were observed in the vessel wall. Perivascular calcifications of calcipheresis-type were also seen. Thyroid inflammation was moderate and fibrosis mild. Two HBFs were identified (1 and $9.5 \mathrm{~mm}$ ) with 14 ossification foci. Abnormal blood vessels were seen around the largest HBF.

Case 5. The patient (71-year-old woman) had undergone right thyroidectomy for compressive cyst. The patient was euthyroid. The medical history was positive for arterial hypertension. The patient also showed vitamin D deficiency $(10.1 \mathrm{ng} / \mathrm{mL})$ as well as hyperuricemia and arthrosis and did not show anemia. An evacuatory punction was followed by reincrease in size of the nodule (3 months afterwards). Postsurgical hypocalcemia occurred and was treated with calcium supplementation. The patient was well at postsurgical consultation (after 3 weeks of follow-up).

Microscopy showed sporadic multinodular goiter with malformative, large, and tortuous blood vessels (intra- and 
extrathyroidal) intermingled with rare nerves. There were no vascular thromboses. Parenchymal nodules, several encapsulated, were hyperplastic and adenoma-like. Calcifications of the internal elastic lamina and media (von Monckeberg sclerosis-type) were observed in the vessel wall. Perivascular calcifications of calcipheresis-type were seen in hyperplastic nodules. There were no vascular thromboses. Inflammation was mild to moderate and fibrosis was mild. One HBF ( $8 \mathrm{~mm})$ was identified. Abnormal blood vessels were seen around the HBF. Adipose involution was multifocal.

3.1. Heterotopic Bone Formation Foci Feature Analysis. The total number of $\mathrm{HBF}$ foci was 28 . The number varied between 1 and 23 foci/thyroid specimen (bilateral: one) and size ranged from inframillimetric to $10 \mathrm{~mm}$. Eighteen (64\%) HBFs were $\geq 2 \mathrm{~mm}$ and six $(21 \%) \geq 5 \mathrm{~mm}$. The shape varied: triangular $(n=2)$, oval $(n=7)$, or rounded $(n=19)$ with a trend for triangular $\mathrm{HBF}$ to correlate with increased size $(P=0.08$, tau $=0.233)$. Twelve HBFs were subcapsular in the thyroid and six occurred in nodules (hyperplastic adenoma-like and one entirely fibroatrophic). When extranodular, HBFs were situated in or in contact with band-patterned fibrosis. Thyroid vesicles, atrophic or not, were in contact with three intranodular and five extranodular HBFs. The intertrabecular tissue was adipose or fibroadipose (seven and $21 \mathrm{HBF}$, resp.), with osteoblast-rimming and megakaryocytes (in two HBFs each). Adipose involution foci were close to some HBFs in Case 2. Intranodular HBFs were more frequently $\geq 2 \mathrm{~mm}$ (4 versus 2 intranodular $\mathrm{HBF}$ of $<2 \mathrm{~mm}$ ). Size correlated with subcapsular location $(P=0.02$, tau $=0.308)$, presence of adipose intertrabecular spaces (as compared to fibroadipose spaces, $P<0.01$, tau $=0.385)$, contact with thyroid vesicles $(P=0.01$, tau $=0.320)$, and presence of adjacent dysmorphic/ malformative vessels $(P=0.01$, tau $=0.435)$.

\section{Discussion}

Here we report five cases of thyroid $\mathrm{HBF}$ occurring in the context of sporadic goiter in euthyroid or hyperthyroid patients. The diagnosis of such lesions was microscopic. The imaging diagnosis was difficult; both micro- and macrocalcifications occurred. Although the HBFs were frequently extranodular and more than $2 \mathrm{~mm}$ in size when intranodular, the imaging features do not allow the precise diagnosis of HBF-type lesions. Whether the subcapsular location, seen in approximately one-third of the HBFs, might be useful remains to be further studied. The main relevance of intrathyroid $\mathrm{HBF}$ is morphological, microscopical. Unlike on ultrasound examination, a misdiagnosis of carcinoma may be made on frozen-section examinations due to the presence of osteoclast-like elements [12].

The histogenesis of such lesions remains a matter of debate. The various thyroid topography, intraparenchymal or subcapsular, of the HBF foci we have seen, occurring in sheet-like fibrosis, more frequently extranodular, suggests a nonneoplastic origin. The presence of multiple, bilateral foci, round to oval more frequently, suggests a dysmetabolic rather than an ectopic nature. The most plausible hypothesis is that of degenerative changes, similar to those reported in the femoral arteries and, less frequently in the carotid, at ages above 60 [13]. Although we have noted von Monckeberg sclerosis-type calcifications both in the media and in the internal elastic lamina in three thyroids, including in intrathyroid location, the morphological aspects we have seen do not indicate a direct vascular origin, as no direct transition zones from blood vessel calcifications to $\mathrm{HBF}$ foci were detected on the different serial and multistep tissue sections. Moreover, malformative vessels lacked within the HBFs and were rare at contact. However, von Monckeberg sclerosis-type calcifications were seen in a perithyroid large vessel at $5 \mathrm{~mm}$ from the HBF in Case 5. An abnormal blood perfusion in the context of enlarged, plunging, goiter-thyroids with modified thyroid-vessel reports, possibly resulting in hypoxia/ischemia might be a favoring factor, as suggested by the presence of sheet-like patterned fibrosis connecting the large malformative tortuous vessels with the HBF foci. The presence of several fibroatrophic vesicular nodules in contact with some HBFs was also highly suggestive of an ischemic nature. Clotting abnormalities were not detected, neither anemia nor hematological disease. Of interest would be the relatively increased frequency of reported cases with intrathyroid hematopoiesis (associated with myelofibrosis or anemia or not) as compared to that of thyroid bone metaplasia [10]. The extensive study of the quasi-totality of thyroidectomy specimens revealed numerous ossification foci (more than 10) in two of the cases, while hematopoietic elements without bone formation lacked. However no hematologic disease was detected in the cases we report. Dysmetabolic factors such as dyslipidemia, diabetes, or fluctuant hyperglycemia and hyperuricemia as well were diagnosed in our cases, younger or older, and could be incriminated in the histogenesis of HBF. Multifocal thyroid adipose involution was seen in three thyroids, the patients' body mass index being above 30 . However these lesions were rarely in direct contact with the adipose intertrabecular spaces of the HBFs to explain a possible participation to the $\mathrm{HBF}$ genesis.

$\mathrm{HBF}$ in the context of abnormal parathyroid functioning has been reported recently in one case [8]. Although we have detected fibroadipose intertrabecular spaces and osteoblastrimming in some HBFs, the patterns of these lesions were not specific neither for hyperthyroid bone formation and resorption nor for hyperparathyroidism-bone modelling [14]. We did not encounter parathyroid function abnormality and the parathyroids were normal preoperatively and during perioperative examination.

Interestingly, the intranodular perivascular or intervesicular pattern of some calcifications observed in some of the nodules suggests a relationship with renal dysfunction, at least for early/initial lesions. Thyroid inflammatory disease may be also incriminated although there was no significant inflammation at the time of surgery. Riedel thyroiditis was ruled out based on microscopic features of the lesions: fibrosis, although focally extensive in two thyroids, remained intrathyroid [15]. Extensive fibrotic scarring may follow the fine-needle aspiration procedure. This hypothesis was ruled out in the cases we report since the punctured nodule was at distance from the HBF. Postradiotherapy fibrosis may be incriminated in the $\mathrm{HBF}$ genesis in Case 4, the patient's 
breast carcinoma being treated with radiotherapy, however, nine years before the thyroid surgery. Other causative agents of extensive fibrosis, such as radioactive iodine treatment, were not identified in any of the cases. The rarity of thyroid $\mathrm{HBF}$ in thyroid goiters rules out also a possible abnormal iodine metabolism. In animals, bone abnormalities are reported to relate to a possible iodine uptake [16]. Interestingly, iodine deficiency can also result in growth abnormalities with destructive alterations in bone and bone marrow, with decrease in hydroxyproline, hexosamines, and phosphomonoesterase-I activities, as well as in disorders of phosphate-calcium metabolism [16]. Whether systemic relationships, possibly indirect, exist between the thyroid HBFs and systemic osteoarticular conditions (diagnosed in three of the cases) such as osteoporosis, chondrocalcinosis, dorsal or lumbar arthrosis, hyperuricemia, and vitamin D deficiency remains to be further investigated. Of note would be the fact that in experimental models on guinea pigs thyroid hormones may result in bone (without cartilage) formation when injected intramuscularly, by a possible osteoblast transportation in muscle fibroblasts [17]. This hypothesis requires further explorations, particularly in humans, despite the simplicity of our observations of thyroid vesicles in contact with $\mathrm{HBF}$ as well as of intrathyroid muscle, however not in direct contact with the HBF.

In conclusion, $\mathrm{HBF}$ may occur in sporadic thyroid goiter. A subcapsular or extranodular location and size $\geq 2 \mathrm{~mm}$ may be useful for the imaging diagnosis. Histogenesis is multifactorial, dysmetabolic conditions, renal dysfunction or vascular abnormalities being possibly involved, without associated parathyroid pathologies. Whether a disturbed iodine metabolism can also be involved requires further investigation.

\section{Conflict of Interests}

The authors declare that they have no conflict of interests.

\section{Acknowledgments}

The authors thank I. Alexandre, V. Ipotesi, N. Akdim, J. Raleche, L. Delagarde, A. Meloni, Professor A. Sapino, Dr. C. Westhoff, Dr. E. Dragoescu, Dr. I. Keller, Dr. SA Polyzos, Dr. T. Leger, MC Portenier, S. Chambris, P. Pausicles, the BIUM, CMDP/APHP, and NCA/Avicenne teams.

\section{References}

[1] S. Akbulut, R. Yavuz, B. Akansu, N. Sogutcu, Z. Arikanoglu, and M. Basbug, "Ectopic bone formation and extramedullary hematopoiesis in the thyroid gland: report of a case and literature review," International Surgery, vol. 96, no. 3, pp. 260$265,2011$.

[2] G. Ardito, G. Fadda, L. Revelli et al., "Follicular adenoma of the thyroid gland with extensive bone metaplasia," Journal of Experimental \& Clinical Cancer Research, vol. 20, no. 3, pp. 443445, 2001.

[3] M. Basbug, R. Yavuz, M. Dablan, and B. Akansu, "Extensive osseous metaplasia with mature bone formation of thyroid gland," Journal of Clinical Endocrinology \& Metabolism, vol. 2, no. 2, pp. 99-101, 2012.

[4] J. S. Chun, R. Hong, and J. A. Kim, "Osseous metaplasia with mature bone formation of the thyroid gland: three case reports," Oncology Letters, vol. 6, no. 4, pp. 977-979, 2013.

[5] K. Cooper and E. M. Barker, "Thyroid carcinosarcoma. A case report," South African Journal of Surgery, vol. 27, no. 5, pp. 192193, 1989.

[6] M. Harsh, P. Dimri, and N. M. Nagarkar, "Osseous metaplasia and mature bone formation with extramedullary hematopoiesis in follicular adenoma of thyroid gland," Indian Journal of Pathology and Microbiology, vol. 52, no. 3, pp. 377-378, 2009.

[7] N. Pontikides, D. Botsios, E. Kariki, K. Vassiliadis, and G. E. Krassas, "Extramedullary hemopoiesis in a thyroid nodule with extensive bone metaplasia and mature bone formation," Thyroid, vol. 13, no. 9, pp. 877-880, 2003.

[8] I. Sayar, A. Isik, E. M. Akbas, H. Eken, and L. Demirtas, "Bone marrow metaplasia in multinodular goiter with primary hyperparathyroidism," The American Journal of the Medical Sciences, vol. 348, no. 6, pp. 530-531, 2014.

[9] G. N. Tzanakakis, C. D. Scopa, M. P. Vezeridis, and A. Vagenakis, "Ectopic bone in multinodular goiter," Rhode Island Medical Journal, vol. 72, no. 5, pp. 171-172, 1989.

[10] C. C. Westhoff, E. Karakas, C. Dietz, and P. J. Barth, "Intrathyroidal hematopoiesis: a rare histological finding in an otherwise healthy patient and review of the literature," Langenbeck's Archives of Surgery, vol. 393, no. 5, pp. 745-749, 2008.

[11] R. G. Micheletti, G. A. Fishbein, J. S. Currier, and M. C. Fishbein, "Mönckeberg sclerosis revisited: a clarification of the histologic definition of Mönckeberg sclerosis," Archives of Pathology \& Laboratory Medicine, vol. 132, pp. 43-47, 2008.

[12] F. Leoni, R. Fabbri, A. Pascarella et al., "Extramedullary haematopoiesis in thyroid multinodular goitre preceding clinical evidence of agnogenic myeloid metaplasia," Histopathology, vol. 28, no. 6, pp. 559-561, 1996.

[13] F. Herisson, M. F. Heymann, M. Chétiveaux et al., "Carotid and femoral atherosclerotic plaques show different morphology," Atherosclerosis, vol. 216, no. 2, pp. 348-354, 2011.

[14] F. Melsen and L. Mosekilde, "Morphometric and dynamic studies of bone changes in hyperthyroidism," Acta Pathologica et Microbiologica Scandinavica, Section A: Pathology, vol. 85, no. 2, pp. 141-150, 1977.

[15] G. Papi and V. A. LiVolsi, "Current concepts on Riedel thyroiditis," American Journal of Clinical Pathology, vol. 121, supplement, pp. S50-S63, 2004.

[16] V. I. Smoliar, "Effect of iodine deficiency on the growth and formation of the bone tissue," Voprosy Pitaniia, vol. 2, pp. 3842, 1983 (Russian).

[17] K. Zarrin, "The bone inducing capacity of syngeneic thyroid tissue in guinea-pig muscle," The Journal of Pathology, vol. 125, no. 2, pp. 99-102, 1978. 


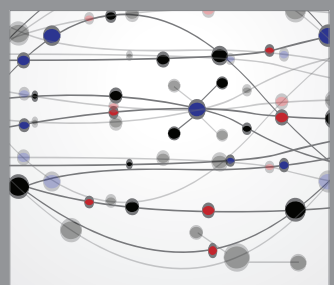

The Scientific World Journal
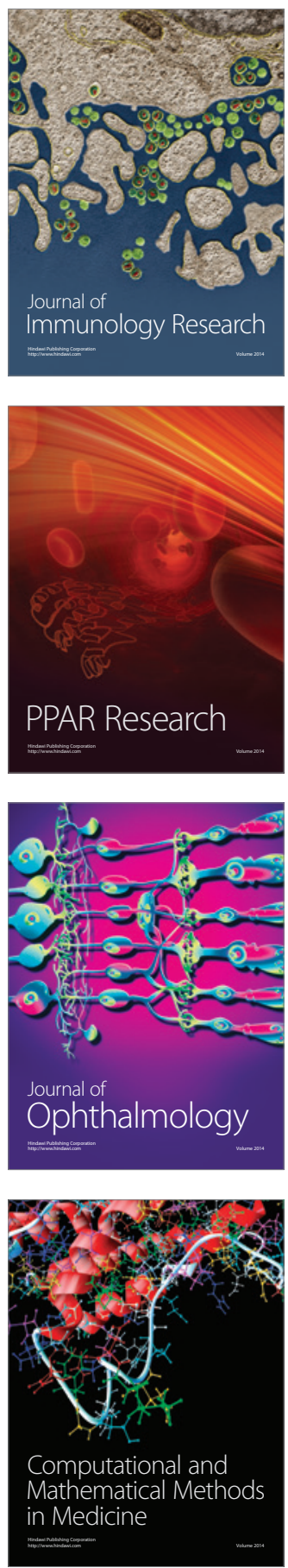

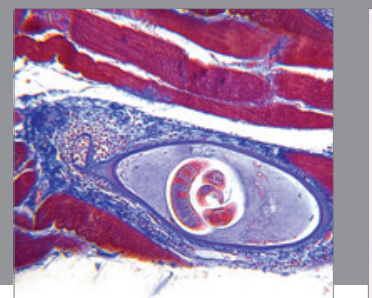

Gastroenterology

Research and Practice
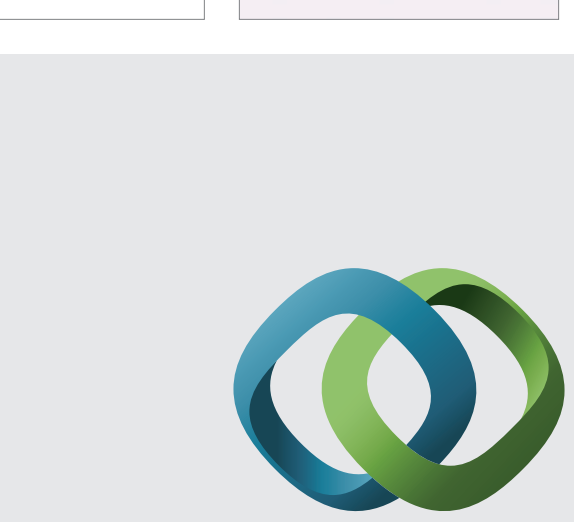

\section{Hindawi}

Submit your manuscripts at

http://www.hindawi.com
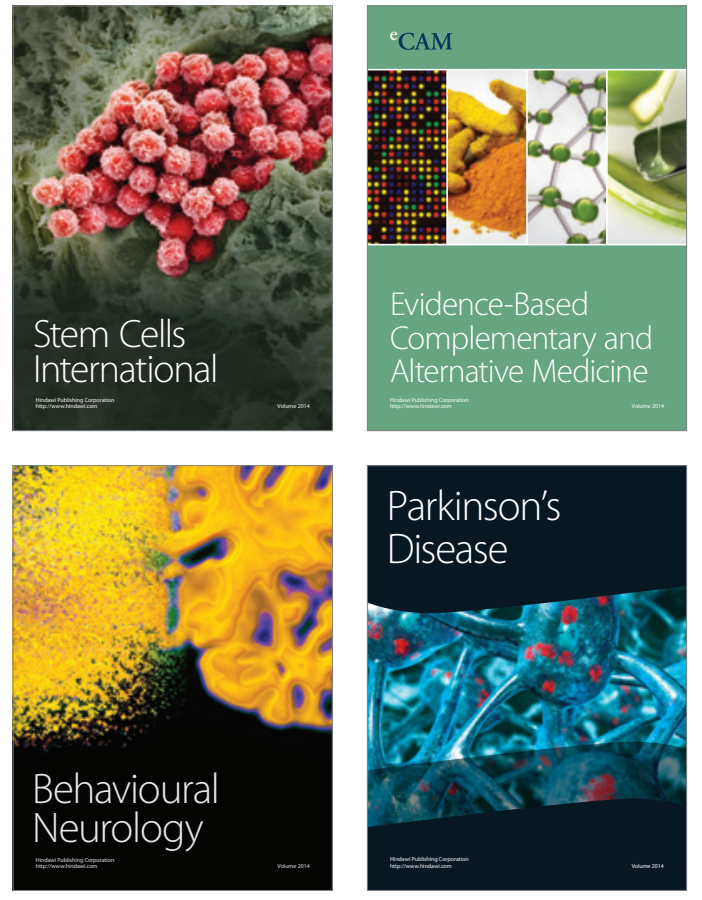
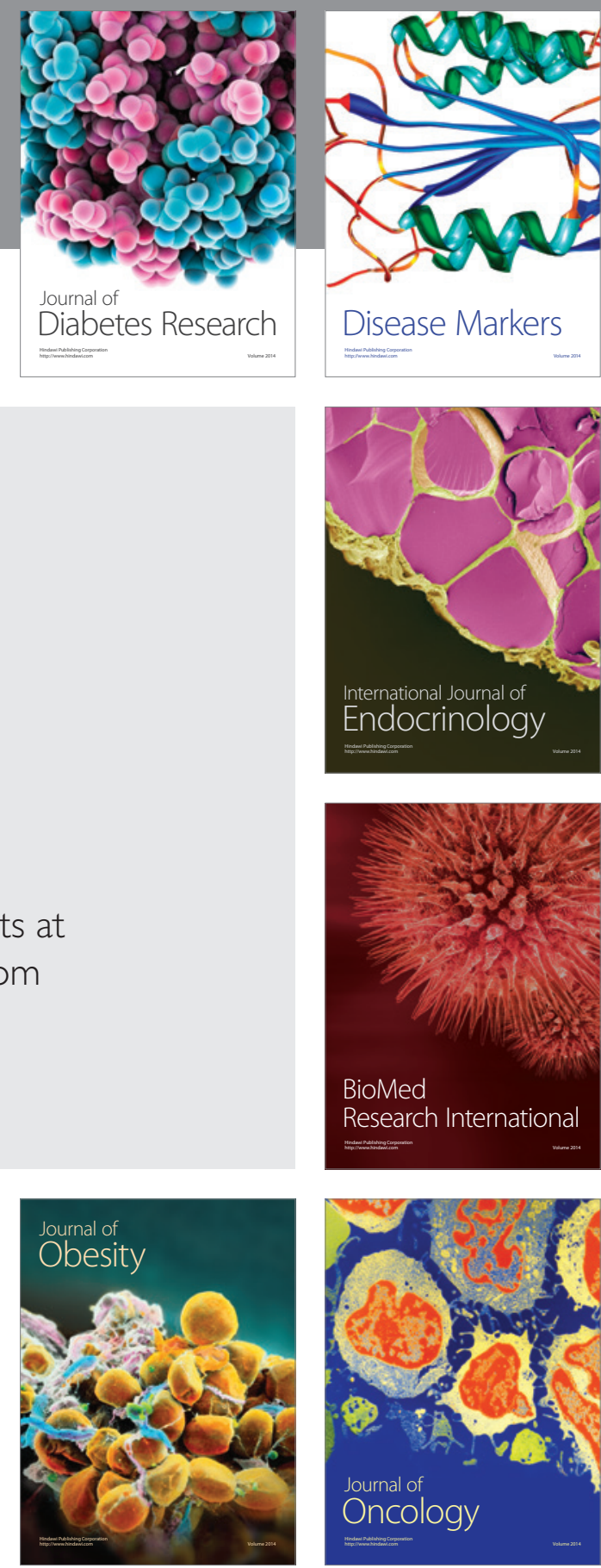

Disease Markers
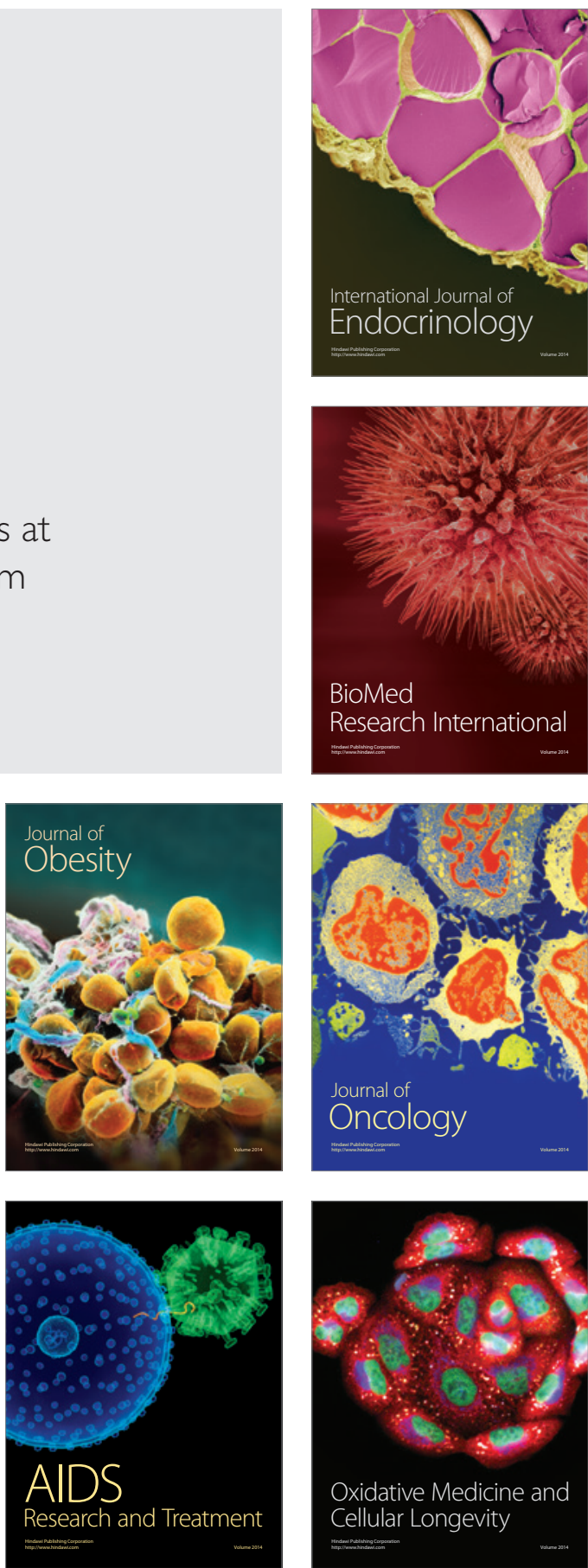